\title{
Communal Crisis and Livelihoods in Akamkpa (A Regression Analysis Study)
}

\author{
Dormcklaims Enamhe ${ }^{1}$, Egbe E. Tangban ${ }^{2, *}$, Thomas A. Omang ${ }^{1}$, \& Mary U. Ojong-Ejoh ${ }^{1}$ \\ ${ }^{l}$ Department of Sociology, University of Calabar, Cross River State, Nigeria \\ ${ }^{2}$ Department of Social Work, University of Calabar, Cross River State, Nigeria
}

\begin{abstract}
Communal crisis and rural community are juxtaposed given the background that Nigeria is anchored upon a conglomeration of cultures with the assumption that cultural heritage should be enjoyable under a benign condition. Unfortunately, societal dynamics emerged with different value systems and new orientations, paving the way for a "jet age" characterized by deviance, conflict and immediate gratification. Nigerian contemporary society is characterized by an identified crisis with common features of destructive, confrontational and violent dimensions, which has led to the loss of lives and property worth millions of naira. Most rural communities have been characterized by unhealthy conflictual situations, which has eventually turned the settlements into theatres of blood and fire emanating from various communal conflicts. The energy of communal violence has assumed a centre stage in our day-to-day interactions. Despite numerous attempts at stemming the tide of such violence, all concerted efforts have proved abortive. The issue is on the ascendency and has also defied remedial measures to curb such negativing phenomenon. This has a lasting and deleterious effect on the social development of rural communities. Social development means investing in people, which requires the removal of barriers so that all citizens can journey toward their dreams with confidence and dignity. The study adopted a crosssectional research survey method using a structured questionnaire as an instrument for data collection to examine the impact of the communal crisis on people's livelihood sources. Data was collected from 800 samples selected from 4 political wards in Akamkpa Local Government Area of Cross River State, Nigeria Descriptive statistics were used to analyze the data. The result from the descriptive analysis was subjected to parametric statistics at 0.05 confidence level. The findings revealed a significant effect of the communal crisis on people's sources of livelihood in Akamkpa local government area of cross river state, Nigeria. Based on this finding, the study calls for government intervention in the way of policy change and social intervention in the affected area and other parts of Nigeria Affected by communal conflict.
\end{abstract}

Keywords: Communal Crisis, People's livelihood, Akamkpa, Regression Analysis

\section{Introduction}

Conflict has been a social reality of human existence. Therefore, it has been inevitable in human societies since prehistoric times due to struggle between various functions of the society to satisfy their interests and needs. One of the significant implications of persistent conflicts is the insecurity of lives and properties, which hinders investments in society. Nigeria, since it returns to democracy, has been laced with some of the most obstinate conflicts. Most of them are constructed from differences in religious and ethnic identities (Karamaga, 2015; Alemika \& Chukwuma, 2000; Ojong, Agba, Njirinze \& Angioha, 2021). Religious and ethnic nationalism has led to conflict about the state, power, unequal allocation of resources, citizenship issues, state collapse, economic decline, land and ethnoreligious clashes. Various regions in Nigeria have been in a statuesque due to a recurrent crisis at region or state illegitimacy, often impairing effort at economic transformation, democratization, national cohesion and stability (James \& Muhammad, 2019; Mayowa, 2005; Ojelabi, Akinwale \& Uyieh, 2021; Omang, 2020).

\footnotetext{
* Corresponding author.

E-mail address: tangbanegbe@unical.edu.ng (First Author)
} 
Akamkpa local government area of cross river state, Nigeria has been in alliance with conflict as a manifestation of political, social, economic, religious, territorial conflicts or conflicts over resources or national interests. Even though they develop in a local framework, they are often connected at regional, national and international levels. Akamkpa local government area has recorded communal crisis leading to loss of lives and properties. The most recent ones are that of June and December 2017. According to Calabar reporters (2017), at least eight persons have reportedly been killed following a communal clash between uyangha and ojor communities in Akamkpa local government area of Cross River state. The commuters along Uyangha and the busy Calabar-Ikom highway were angry youth with charms brandished guns and machetes.

Again, in December 2017, the same communities had another phase of crisis. According to Calabar reporters, houses and properties were razed down, commuters plying the road were stranded as the tempo of the crisis skyrocketed. In contrast, the two neighbouring communities were encapsulated hostage. In affirmative, Edem (2017) ascertained that most members of these communities were locked inside their houses without an escape route.

This conflict did not occur in a vacuum. Several factors have been responsible for these conflicts. Their variations, nature and location of such conflict remain imperative. It is also important to note that most conflicts in some regions like the middle belt in Nigeria have almost the exact causes or sources due to several small tribes who want to identify with their cultures, protect their political interest, religion and ethnicity (Ojong-Ejoh, Iji, \& Angioha, 2019; Raimi, 2010; Ndem, Angioha, \& Dike, 2020; Omang, Okpa, Okoi, \& Iniama, 2020). Alemika (2012) stressed that it is challenging to differentiate which conflict is primarily engendered by economic, ethnic, religious, and political competition.

These conflicts have standard features, their confrontational, destructive and violent dimension, which lead to the loss of lives and properties of people who live communal and harmonious lives. The effect of violence has a long-lasting retrogressive challenge on the development of rural communities in terms of economic, social, political, and environmental sustainability. This study is aimed at examining the impact of this communal crisis on sustainable business practice.

\section{Materials and Methods}

\subsection{Study Design and Measurement}

This was a cross-sectional study that adopted data from a survey that was carried out between June and September with the aid of a structured self-developed interview questionnaire that was designed in a Likert Scale format of four Point comprising "Strongly Agreed", "Agreed", "Disagreed" and "Strongly Disagreed". A sample size of 400 was adopted for the study. This was determined by the Survey Monkey Sample Size Determinant Technique at a 99-confidence level. The 800 samples were selected using the cluster, purposive and simple random sampling technique. From a cluster of 10, based on the ten wards that make up Akamkpa Local Government area, four political wards were conveniently selected because of being the most affected wards by the Communal Crisis. The wards are Uyangha, Oban, Ojor, and Mbarakom. Two (2) communities were conveniently selected, each from the selected political wards. The communities are those directly affected by the communal crisis. From the eight selected communities, 100 samples were selected from each of the selected wards using random sampling. The criteria for sample selection is being a member of the affected communities, above 20 years and must have firsthand knowledge of the communal crisis.

\subsection{Study Settings}

Akamkpa is a local Government in Southern Cross River State, Nigeria. With a landmass of 5,003square kilometres and a population of 151,125, according to the last census count in 2005 (NPC, 2006; Uyilowohma, Okon, \& Unim, 2021; Ayuk, Chimaobi, Omang, \& Nwankwo, 2020). The area has an average temperature of 25.6 degrees centigrade and a landscape that consists of sizeable fertile land rich in mineral resources. Politically the Local Government area was created in 1976, with its head quatres at Akamkpa town. The two most prominent ethnic groups in the area are the Ejagham and Dusaya Iyoug. It has a rich agricultural heritage, with most of the inhabitant's practising agriculture as a source of livelihood. 


\subsection{Data Analysis}

Data collected from the study samples were checked for completeness and then entered into IBM SPSS (Statistical Package for Social Science) version 21 for cleaning and data analysis. Data were analyzed using Bivariate Analysis using regression analysis at 0.05 confidence level.

\section{Findings}

\subsection{Descriptive Analysis}

The study was to analyze the impact of the communal crisis in Akamkpa on people's livelihood sources. A structured instrument developed in a four-point Likert Scale format designed by the researchers was distributed to four political wards in Akamkpa Local Government area. Eight hundred (800) instruments were distributed, and 774 was returned or filled without missing items. This was used for analysis. Two variables were identified from the topic under study, and the questions raised were developed. The collected instruments were analyzed using descriptive analysis. Descriptive statistics involving frequency and simple percentages, responses are presented in table 1.

Table 1. Responses on Akamkpa communal crisis and people's livelihood sources

\begin{tabular}{|c|c|c|c|c|c|c|}
\hline $\mathrm{S} / \mathrm{N}$ & Statements & $\mathrm{N}$ & $\begin{array}{c}\text { SA } \\
\mathrm{F}(\%)\end{array}$ & $\begin{array}{c}\mathrm{A} \\
\mathrm{F}(\%)\end{array}$ & $\begin{array}{c}\mathrm{D} \\
\mathrm{F}(\%)\end{array}$ & $\begin{array}{c}\text { SD } \\
\mathrm{F}(\%)\end{array}$ \\
\hline 1 & $\begin{array}{l}\text { The communal crisis between Uyanga } \\
\text { and Ojor affected all activities in the } \\
\text { affected communities and neighbouring } \\
\text { communities }\end{array}$ & 774 & $\begin{array}{c}286 \\
(36.95)\end{array}$ & $\begin{array}{c}255 \\
(32.94)\end{array}$ & $\begin{array}{c}115 \\
(14.85)\end{array}$ & $\begin{array}{c}118 \\
(15.24)\end{array}$ \\
\hline 2 & $\begin{array}{l}\text { Much destruction took place during the } \\
\text { crisis }\end{array}$ & 774 & $\begin{array}{c}277 \\
(35.78)\end{array}$ & $\begin{array}{c}242 \\
(31.26)\end{array}$ & $\begin{array}{c}80 \\
(10.33)\end{array}$ & $\begin{array}{c}175 \\
(22.60)\end{array}$ \\
\hline 3 & $\begin{array}{l}\text { Many people remained indoors during } \\
\text { the crisis }\end{array}$ & 774 & $\begin{array}{c}241 \\
(31.13)\end{array}$ & $\begin{array}{c}188 \\
(24.28)\end{array}$ & $\begin{array}{c}164 \\
(21.18)\end{array}$ & $\begin{array}{c}181 \\
(23.38)\end{array}$ \\
\hline 4 & $\begin{array}{l}\text { People were unable to go to their } \\
\text { various farms }\end{array}$ & 774 & $\begin{array}{c}262 \\
(33.85)\end{array}$ & $\begin{array}{c}228 \\
(29.45)\end{array}$ & $\begin{array}{c}155 \\
(20.02)\end{array}$ & $\begin{array}{c}126 \\
(16.27)\end{array}$ \\
\hline 5 & $\begin{array}{l}\text { The weekly markets did not take place } \\
\text { as a result of the crisis }\end{array}$ & 774 & $\begin{array}{c}9 \\
(1.16)\end{array}$ & $\begin{array}{c}12 \\
(1.55)\end{array}$ & $\begin{array}{c}85 \\
(10.98)\end{array}$ & $\begin{array}{c}668 \\
(88.88)\end{array}$ \\
\hline 6 & $\begin{array}{l}\text { Businesses were unable to run smoothly } \\
\text { during the crisis }\end{array}$ & 774 & $\begin{array}{c}264 \\
(34.10)\end{array}$ & $\begin{array}{c}256 \\
(33.07)\end{array}$ & $\begin{array}{c}208 \\
(26.87)\end{array}$ & $\begin{array}{c}46 \\
(5.94)\end{array}$ \\
\hline 7 & $\begin{array}{l}\text { People were unable to care for their } \\
\text { family members }\end{array}$ & 774 & $\begin{array}{c}311 \\
(40.18)\end{array}$ & $\begin{array}{c}258 \\
(33.33)\end{array}$ & $\begin{array}{c}118 \\
(15.24)\end{array}$ & $\begin{array}{c}87 \\
(11.24)\end{array}$ \\
\hline
\end{tabular}

Table 1 shows participants' responses on Akamkpa communal crisis and people's livelihood sources. The opinion of the respondents' was as follows; the communal crisis between Uyanga and Ojor affected all activities in the affected communities and neighbouring communities; strongly agreed $=286(36.95)$, agree $=255$ (32.94), disagree $=115$ (14.85), strongly disagree $=118(15.24)$. On whether A lot of destruction took place during the crisis; strongly agree $=277(35.78)$, agree $=242(31.26)$, disagree $=80(10.33)$, and strongly disagree $=175(22.60)$. Similarly, asked if A lot of people were remained indoors during the crisis; strongly agree $=241(31.13)$, agree $=188(24.28)$, disagree $=164$ 
(21.18), and strongly disagree $=181$ (23.38). On whether People were unable to go to their various farms; strongly agree $=262(33.85)$, agree $=228(29.45)$, disagree $=155(20.02)$, strongly disagree $=126(16.27)$.

However, when asked if the weekly markets did not take place as a result of the crisis; strongly agree $=9(1.16)$, agree $=12(1.55)$, disagree $=85(10.98)$, strongly disagree $=668(88.88)$. Furthermore, on whether Businesses were unable to run smoothly during the crisis; strongly agree $=264$ (34.10), agree $=256(33.07)$, disagree $=208(26.87)$, strongly disagree $=46$ (5.94). As for whether People were unable to care for their family members; strongly agree $=311(40.18)$, agree $=258$ (33.33), disagree $=118(15.24)$, and strongly disagree $=87(11.24)$.

\subsection{Parametric Statistics}

The result from the descriptive analysis was subjected to parametric statistics using simple Linear regression analysis. The independent variable in this hypothesis is a communal crisis, while the dependent variable is people's livelihood sources. Both variables were measured continuously, and inferential statistics involving simple linear regression was used to test the hypothesis at .05 Alpha level. The result is presented in table 2.

Table 2: Summary Simple Linear Regression Analysis: Communal Crisis and People's Livelihood Sources

\begin{tabular}{lcccccccc}
\hline \multicolumn{1}{c}{ Model } & $\begin{array}{c}\text { Sum of } \\
\text { Squares }\end{array}$ & df & $\begin{array}{c}\text { Mean } \\
\text { Square }\end{array}$ & F & R & R Square & $\begin{array}{c}\text { Adjusted R } \\
\text { Square }\end{array}$ & Sig \\
\hline Regression & 1307.663 & 2 & 1307.663 & 49.864 & $.246^{\mathrm{a}}$ & .061 & .059 & $.000^{\mathrm{a}}$ \\
$\begin{array}{l}\text { Residual } \\
\text { Total }\end{array}$ & 20245.429 & 772 & 26.225 & & & & & \\
\hline
\end{tabular}

a. Predictor's variable: (Constant), AKAMKPA COMMUNAL CRISIS

b. Dependent Variable: PEOPLE'S LIVELIHOOD SOURCES

Table 2 presents the result of data analysis on the relationship between Communal Crisis and People's Livelihood Sources. Results revealed R-value of $.246^{\mathrm{a}, \mathrm{R} 2}=.061$, adjusted $\mathrm{R}^{2}=.059, \mathrm{p}=.000^{\mathrm{a}}$ and $<.05$ for relationship Communal Crisis and People's Livelihood Sources. The R-value (Correlation coefficient) is a standardized measure of an observed degree of relationship between variables. It is a commonly used measure of the size of an effect, and that values of \pm .1 represent a small effect, \pm .3 is a medium effect, and \pm .5 is a large effect.

The $\mathrm{R}^{2}$-value of .061 implies that $6.1 \%$ of total variance is accounted for by the predictor variable (communal crisis). The regression ANOVA revealed that the $\mathrm{F}(2,772) 49.864 ; \mathrm{p}<.000$ is significant; therefore, the null hypothesis was rejected. This implies a linear relationship (association) between the predictor variable (communal crisis) and people's livelihood sources. The adjusted $\mathrm{R}^{2}(.059)$ shows some shrinkage of the unadjusted $\mathrm{R}$-value (.061), indicating that the model could generalise the population. Based on the results, it was concluded that; parents' Akamkpa Communal crisis significantly affected people's source of livelihood.

\subsection{Discussion of Findings}

Data collected was analyzed using descriptive and parametric statistics. From the descriptive analysis, 69.89 per cent of the study sample revealed that the communal crisis between Uyanga and Ojor affected all activities in the affected communities and neighbouring communities. Most of the subjects (67.04\%) agreed that much destruction occurred during the conflict, as community member houses got burnt, people were killed, and people's goods were destroyed. Also, from the analysis, it was discovered that according to the response of the study subjects (63.3\%), many people are unable to go about their daily business. Even though most (99.86\%) reported that the local market still held regularly, the business did not go as planned.

The result from the parametric statistics was subjected regression analysis at 0.05 confidence level Results revealed an R-value of $.246^{\mathrm{a}, \mathrm{R} 2}=.061$, adjusted $\mathrm{R}^{2}=.059, \mathrm{p}=.000^{\mathrm{a}}$ and $<.05$ for relationship Communal Crisis and People's Livelihood Sources. The $\mathrm{R}^{2}$-value of .061 implies that $6.1 \%$ of total variance is accounted for by the predictor variable (communal crisis). This implies a linear relationship (association) between the predictor variable (communal crisis) and 
people's livelihood sources. This result aligns with Howell (2014), who stated that communal crisis negated peaceful co-existence, the law as a crisis militate against the consolidation of democracy and social co-existence. This, in turn, impact the social and economic wellbeing of a nation and creates imbalances in social relations. Communal crisis brings a complex set of events such as poverty, ethnic or religious grievances which affects the social relationship of people in the society. Similarly, Marx (2008) posits that violence, particularly communal crisis, represents a disturbance movement to the system's political equilibrium and peaceful co-existence.

In the same vein, Alubo (2011) asserts that the refugee problems that accompany these disturbances also have implications for target attainment and access to social development such as education, reduction in maternal mortality and childhood death, and other aspects of productive health. Indeed, the mass rape of the female population in the area engulfed by violence fuels the spreading of HIV/AIDS, which is already a high prevalence and regarded as a social problem in Nigeria.

More importantly, the continued eruption of communal crisis has implications for national peace and security, thereby threatening the dissolution of a country policy. Communal crisis negatively impacts many forms of development, such as the inability of people to interact with one another, creating unhealthy child growth and development. In such an epoch of communal crisis, inhabitants (people) abandon their ethnic, value systems (culture heritage), religion and tradition to pledge allegiance to new norms unproven by the state. This scenario has plunged people into a more profound crisis, poor interaction resulting in fierce elimination, putting fellow citizens under repressive measures threatening the rule of law, personal freedom and human rights.

\section{Conclusion and Recommendation}

The findings of this research concluded that the Akamkpa communal crisis had affected people's source of livelihood. Based on these findings, it is recommended that; Adequate measures should be put in place by government and community rulers to ensure that communal crises are prevented. There should be economic empowerment through skill acquisition for people living in rural areas. Permanent measures should be taken to forestall peaceful co-existence between warring communities; government security apparatus should be a standard feature in such warlike regions.

\section{References}

Alemika, E. O. (1995). “Criminology and the Philosophy of Policing”, in Tamuwo, T.N. et al. (Eds.) Policing in Nigeria: Past, Present and Future, Lagos: Malthouse.

Alemika, E. O. and Chukwuma, I. C. (2000). Police-Community Violence in Nigeria, Lagos and Abuja: Centre for Law Enforcement Education and National Human Rights Commission

Ayuk, A. A., Chimaobi, O., Omang, T. A., \& Nwankwo, E. E. (2020). Continuous Ex-Offenders' Reformation and Avoidance of Recidivistic Acts in Nigeria. International Journal of Criminology and Sociology, 9, 16311637.

James, T. F., \& Muhammad, A. (2019). Communal Conflict and National Security in Nigeria: Selected Case Studies. SSRN Electronic Journal. Published. https://doi.org/10.2139/ssrn.3471404

Karamaga, A. (2015). Bridging Denominational Divides in Africa. The Ecumenical Review, 67(4), 505-513. https://doi.org/10.1111/erev.12189

Mayowa, O. A. (2005). State and Ethno-Communal Violence in Nigeria: The Case of Ife-Modakeke. Africa Development, 26(1). https://doi.org/10.4314/ad.v26i1.22136

Ndem, M.A., Angioha, P.U., \& Dike, E. (2020). Improving the socio-economic wellbeing of rural people: Analysis of the impact of the community and social development project (CSDP) in Odukpani Local Government Area of Cross River State, Nigeria. Asian Journal of Applied Sciences, 8(2), 88-94 
Ojelabi, E. O., Akinwale, O. E., \& Uyieh, J. (2021). Communal clash and conflict management in Nigeria: An investigation of Erin Ile and Offa Crisis, 2006-2018. Local Development \& Society, 2(1), 3-21. https://doi.org/10.1080/26883597.2020.1864227

Ojong, F. E., Agba, A. M. O., Njirinze, C. J., \& Angioha, P. U. (2021). Ethno-communal crisis and its implication on food security and business activities in Nigeria. SAINSMAT: Journal of Applied Sciences, Mathematics, and Its Education, 10(1), 11-20. https://doi.org/10.35877/sainsmat1012102021

Ojong-Ejoh, M.U., Iji, M.E., \& Angioha, P.U. (2019). "Curing socioeconomic ills in Obudu Local Government Area: An assessment of non-governmental agencies activities". Journal of Social Service and Welfare, 1(2), 2019, pp. 38-45.

Omang, T. A. (2020). The extent of Centrifugal Underdevelopment in Bekwara: A Household Descriptive Survey. IJOInternational Journal of Social Science and Humanities Research, 3(12), 64-82.

Omang, T. A., Okpa, J. T., Okoi, O. N., \& Iniama, J. (2020). Women Barriers and Empowerment Opportunities in The Nigerian Context. Pertanika Journal of Social Sciences and Humanities, 28(4). https://doi.org/10.47836/pjssh.28.4.37

Raimi, A. (2010). Identity issues in urban ethnic-communal con! ICT in Africa: an empirical study of the life-modakeke crisis in Nigeria. African Sociological Review / Revue Africaine de Sociologie, 13(2). https://doi.org/10.4314/asr.v13i2.60406

Uyilowohma, O. E. M., Okon, B. A., \& Unim, A. P. (2021). Uplifting the SocioeconomicSocioeconomic Life of Rural People through the Provision of Credit facilities and Entrepreneurship Development: The Role of CUSO International. FWU Journal of Social Sciences, 15(1). 